\title{
Crack features of flexural members strengthened by carbon fiber sheet bonded with inorganic adhesive after fire
}

\author{
Fuxiong Wan \\ Architectural and Civil Engineering Institute, Kunming University of \\ Science and Technology, Kunming, China \\ wanfuxiong2011@163.com
}

\begin{abstract}
.
Crack distribution and Extension is the important mechanical features of flexural members strengthened by carbon fiber sheet bonded with inorganic adhesive after fire, which is helpful to understand all-round mechanical performance of the style of structural members. Four strengthened beams and four strengthened slabs are tested, and their crack development with loading increase is recorded in detail. The test and analysis results show that, For beams strengthened by carbon fiber sheet bonded with an inorganic adhesive which experienced fire, bending cracks are obviously more than bending and shear cracks, which is because that temperature of lower area of beam section is higher than that of upper area. CFS has a role of restricting crack production and development. The more CFS is, the bigger crack width is and the smaller crack distance is.

Keywords: an inorganic adhesive; RC member; Carbon Fiber Sheet; crack; after fire

\section{Introduction}

Currently, organic epoxy adhesive is usually used in concrete structures strengthened with Carbon Fiber Sheets, but its softening temperature is too low, most of which typically vary from $60 \mathrm{C}$ to $80 \mathrm{C}^{[1-3]}$. This shortcoming makes it difficult to meet the requirement of fire endurance. Therefore, an inorganic adhesive, whose strength at $600 \mathrm{C}$ is not lower than that at normal room temperature, is developed to bond Carbon Fiber Sheet in order to strengthen reinforced concrete members ${ }^{[4,5]}$. During research of mechanical experiment of members strengthened by carbon fiber sheet bonded with an inorganic adhesive which experienced fire, crack development with loading increase is recorded in detail, which is helpful to understand all-round mechanical performance of the style of structural members.
\end{abstract}




\section{Design of specimens}

Four strengthened beams and four strengthened slabs are designed for the test. Three beams have the same size, $4400 \mathrm{~mm}$ in length, $150 \mathrm{~mm}$ in width and $350 \mathrm{~mm}$ in height. Four slabs have the same size, $4400 \mathrm{~mm}$ in length, $600 \mathrm{~mm}$ in width and $120 \mathrm{~mm}$ in height. Actual span of each beam and slab is $3500 \mathrm{~mm}$. Longitudinal steel bar of each beams (beam1, beam2, beam3 and beam4), with diameter of $12 \mathrm{~mm}$, has a $25 \mathrm{~mm}$ thick clear cover. Its yield strength and ultimate strength are respectively $375 \mathrm{Mpa}$ and $555 \mathrm{Mpa}$. Its Elastic module is $2.01 \times 10^{5} \mathrm{Mpa}$. Longitudinal steel bar of each slab(slab1,slab2 and slab3 and slab4), with diameter of $12 \mathrm{~mm}$ and $10 \mathrm{~mm}$, has a $15 \mathrm{~mm}$ thick clear cover. The yield strength with diameter of $12 \mathrm{~mm}$ and $10 \mathrm{~mm}$ is respectively 396 and 390 , and their ultimate strength are respectively $490 \mathrm{Mpa}$ and $499 \mathrm{Mpa}$. Its Elastic module is $2.0 \times 10^{5}$ Mpa. The strength of the standard concrete cubic $(100 \mathrm{~mm} \times 100 \mathrm{~mm} \times 100 \mathrm{~mm})$ of all members is 32MPa from the corresponding test. A layer Carbon Fiber Sheet (CFS) is bonded on the down surface of the each member. Its strength and Elastic module are respectively $4223 \mathrm{Mpa}$ and $2.42 \times 10^{5} \mathrm{Mpa}$. $250 \mathrm{~mm}$ wide U-shape CFS stirrups are arranged along long direction of each member. Design scheme of specimens is shown as Fig.1. The CFS is $0.111 \mathrm{~mm}$ thick. An inorganic adhesive developed by the author's team is used to bond CFS. Temperatures the inorganic adhesive experienced at center point of down surface of members are about 300 470Cfor beams and about 200 300C for slabs at standard fire test. Mechanical experiment of all members which experienced fire is done, as shown as Fig.2.

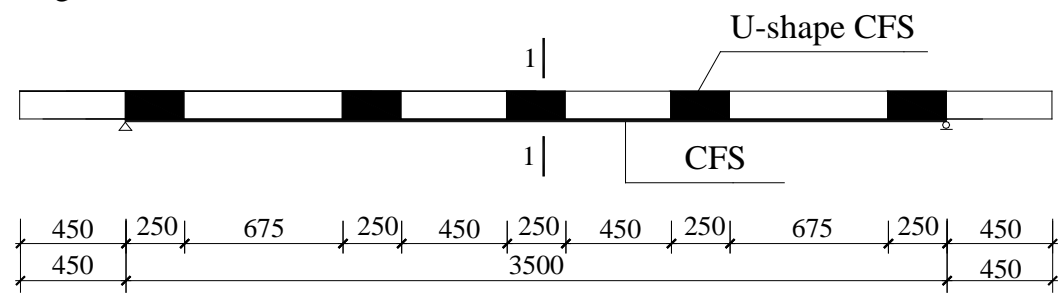

(a) Beam1 and Beam2

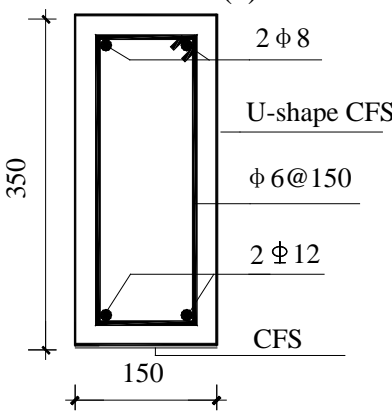

$\underline{1-1}$

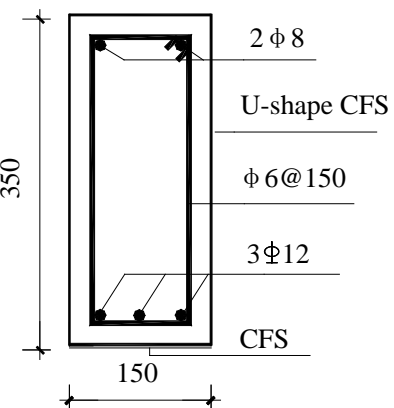

$\underline{1-1}$

(b) Beam3 and Beam4 


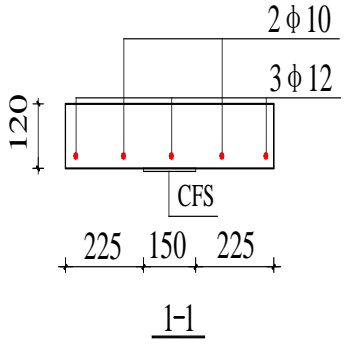

(c) Slab1

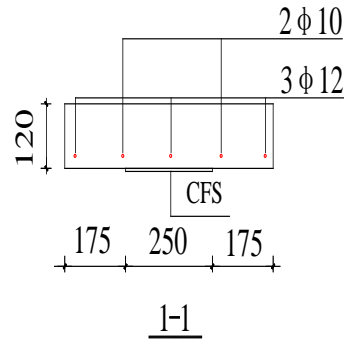

(d)Slab2

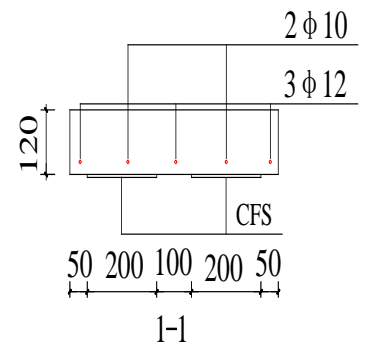

(e) Slab3 and slab4

Fig.1 Design scheme of specimens (units: mm)

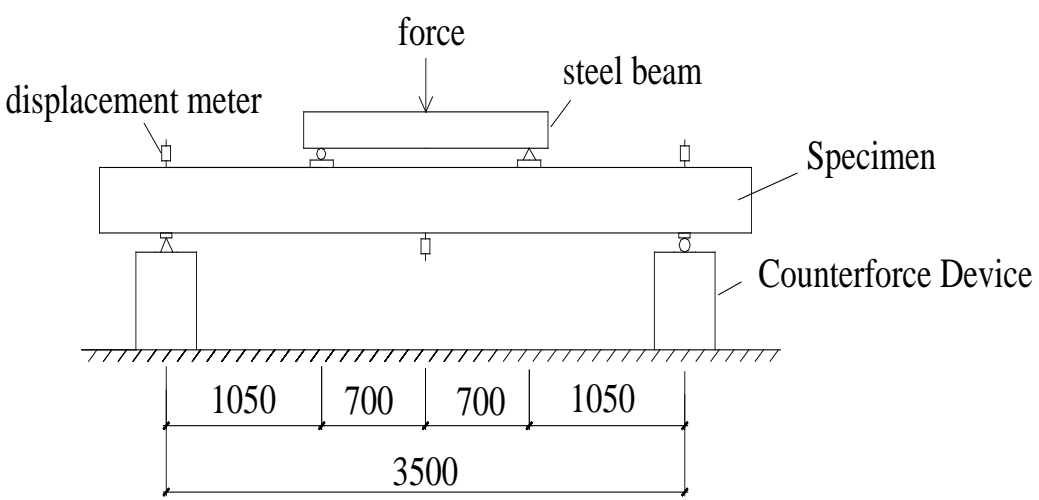

Fig.2 Scheme of test (units: mm)

\section{Typical crack distribution of specimens}

As loading increases, the specimens crack firstly, then failure. CFS is broken, peel and tear when specimens failure. The typical crack distribution of beam and slab is shown as fig.3. From the fig3, we can found that the crack is vertical to the cross section, which is caused by moment.

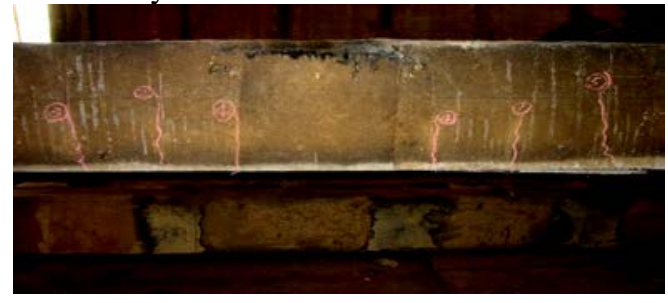


(a) crack of side surface of beam

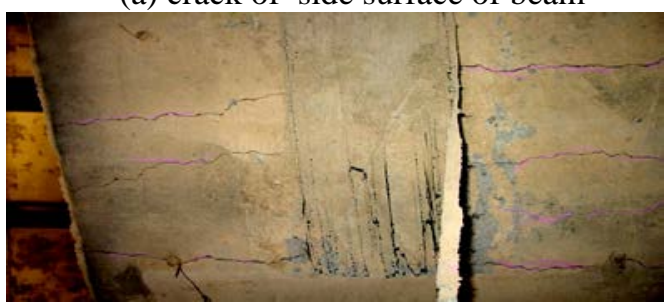

(b) crack of down surface of slab

Fig.3 Tipical crack distribution of beam and slab

\section{Crack development and ditribution of beams}

Crack development and distribution of each beam is shown as fig.4. Code of each crack on one side surface of beam represents crack appearing sequence, the width of each crack is shown under the corresponding crack. Specimen beam 4 is covered by coating, so its crack development is not recorded. We can see from fig. 4 that the crack is vertical to the cross section, which is caused by moment, except that specimen beam 2 has two bending and shear cracks, which is oblique to the cross section. Crack appearance is mainly relative to shear span ratio of beam and temperature concrete experienced. The fact that bending cracks are obviously more than bending and shear cracks is because that temperature of lower area of beam section is higher than that of upper area, which is helpful for bending crack appearance from lower zone of beam surface.

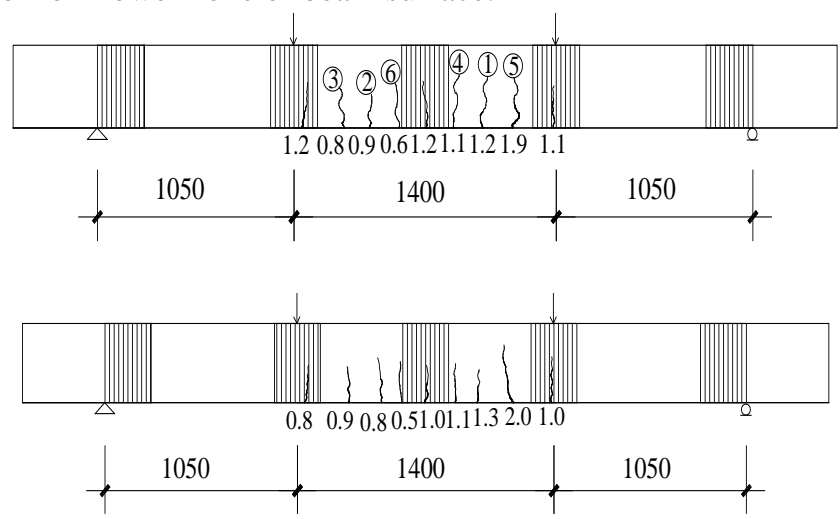

a) Beam1

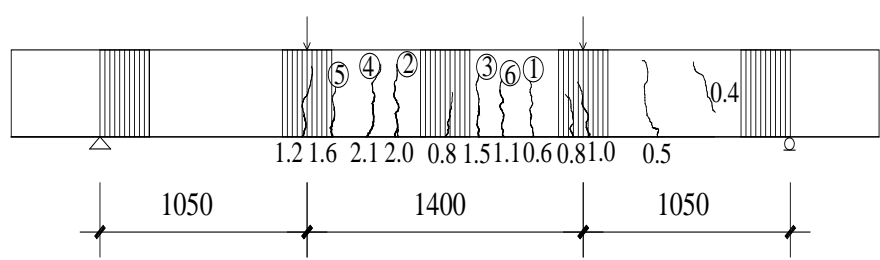




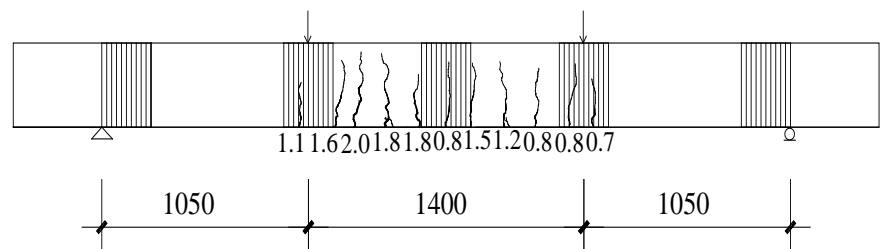

b) Beam2

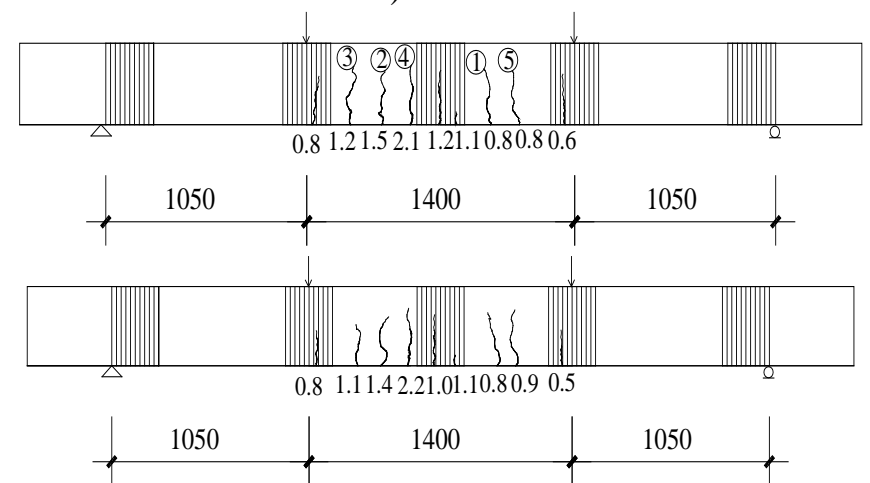

c) Beam3

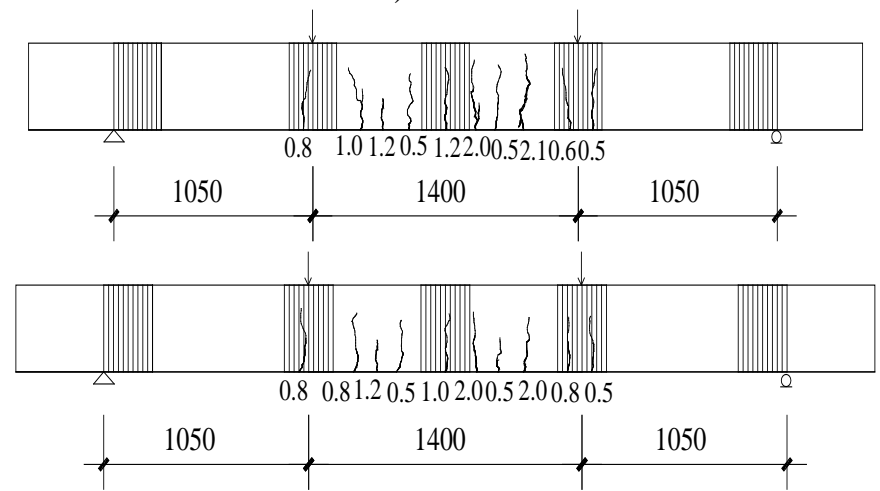

d) Beam4

Fig.4 Crack development and distribution of beam

Cracks width of three beams changes with loading increasing, as shown as table 1.

Table 1 Crack width of test beams

\begin{tabular}{|c|c|c|c|c|c|c|c|c|}
\hline \multirow{2}{*}{ beam } & \multirow{2}{*}{$\begin{array}{l}\text { Moment } \\
/ \mathrm{kN} \cdot \mathrm{m}\end{array}$} & \multicolumn{6}{|c|}{ Crack width /mm } & \multirow{2}{*}{$\begin{array}{c}\text { Average } \\
\text { crack } \\
\text { width } \\
/ \mathrm{mm}\end{array}$} \\
\hline & & (1) & (2) & (3) & (4) & (5) & (6) & \\
\hline \multirow{2}{*}{ beam1 } & 19.85 & 0.20 & 0.13 & 0.16 & 0.20 & 0.31 & 0.10 & 0.18 \\
\hline & 21.95 & 0.22 & 0.15 & 0.18 & 0.22 & 0.33 & 0.11 & 0.20 \\
\hline
\end{tabular}




\begin{tabular}{ccccccccc} 
& 23 & 0.23 & 0.15 & 0.19 & 0.23 & 0.34 & 0.12 & 0.21 \\
& 24.05 & 0.24 & 0.17 & 0.20 & 0.24 & 0.35 & 0.13 & 0.22 \\
\hline \multirow{6}{*}{ beam2 } & 20.9 & 0.13 & 0.24 & 0.20 & 0.25 & 0.18 & 0.10 & 0.18 \\
& 21.95 & 0.14 & 0.25 & 0.20 & 0.27 & 0.19 & 0.11 & 0.19 \\
& 24 & 0.15 & 0.26 & 0.21 & 0.29 & 0.20 & 0.11 & 0.20 \\
& 24.05 & 0.16 & 0.28 & 0.22 & 0.30 & 0.21 & 0.12 & 0.21 \\
\hline \multirow{3}{*}{ beam3 } & 27.2 & 0.14 & 0.20 & 0.16 & 0.26 & 0.09 & - & 0.17 \\
& 29.3 & 0.15 & 0.21 & 0.17 & 0.27 & 0.10 & - & 0.18 \\
& 31.4 & 0.16 & 0.23 & 0.18 & 0.29 & 0.11 & - & 0.19 \\
& 33.5 & 0.18 & 0.25 & 0.20 & 0.31 & 0.12 & - & 0.21 \\
\hline
\end{tabular}

\section{Crack development and ditribution of slabs}

Crack distribution of each slab is shown as fig.5. Width of each crack is shown under the corresponding crack. Crack width and distance of specimen B3 and B4 is smaller than that of other slabs, which is because that CFS of B3 and B4 is wider than others, which has a role of restricting main crack development and is beneficial to produce more new crack.

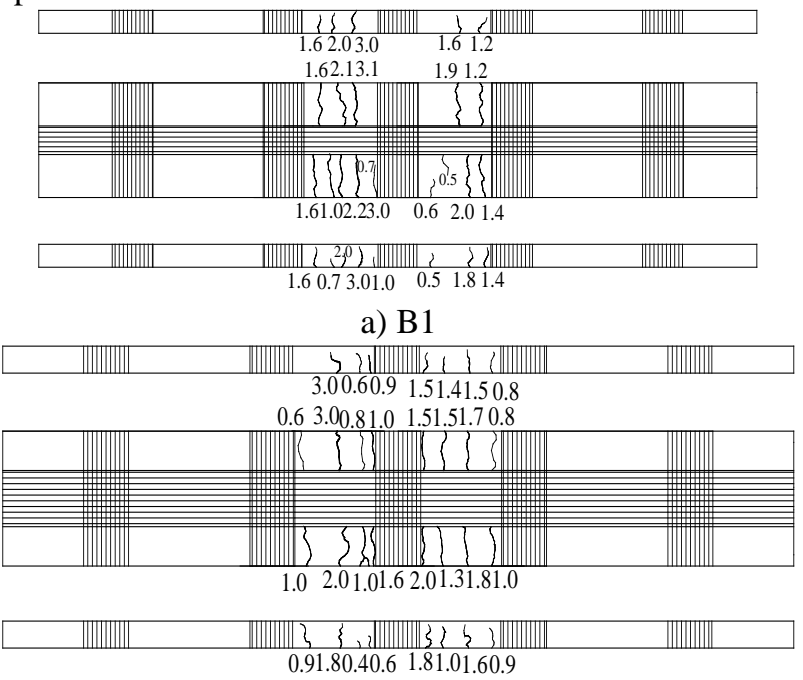

b) $\mathrm{B} 2$ 


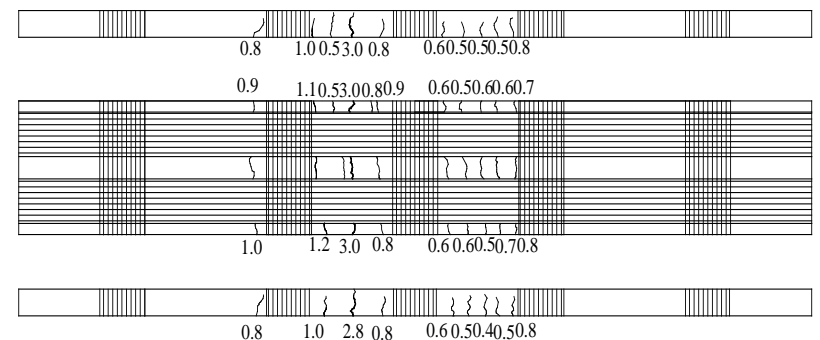

c) B3

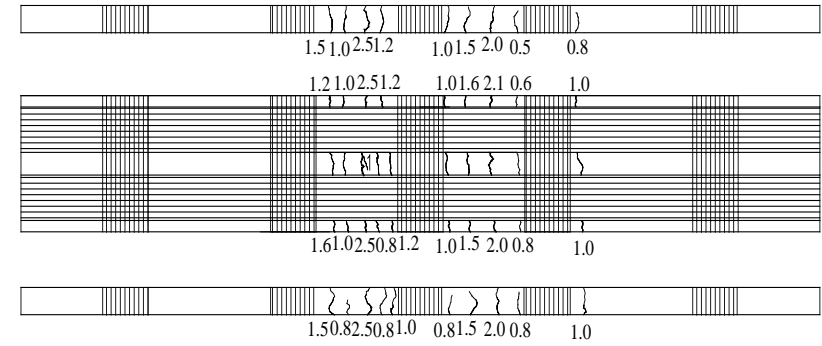

d) B4

Fig.5 Crack distribution of slabs

\section{Conclusions}

1)For beams strengthened by carbon fiber sheet bonded with an inorganic adhesive which experienced fire, bending cracks are obviously more than bending and shear cracks, which is because that temperature of lower area of beam section is higher than that of upper area.

2) The more CFS is, the bigger crack width is and the smaller crack distance is. CFS has a role of restricting crack production and development.

\section{Acknowledgements}

This work was financially supported by National Natural Science Foundation of China ( 50678050).

\section{References}

[1]V. K. R. Kodur, L. A. Bisby, M. F. Green. Experimental Evaluation of the Fire Behaviour of Insulated Fibre-Reinforced-Polymer-Strengthened Reinforced Concrete Columns. Fire Safety Journal. 2006,41(7):547 557

[2]B. K. William. Fire Performance of FRP-Strengthened Reinforced Concrete Flexural Members. PhD thesis, Queen's University. 2004:41;76 177

[3]B. Williams, L. Bisby, V. Kodur, M. Green, E. Chowdhury. Fire Insulation Schemes for FRP-Strengthened Concrete Slabs. Composites Part A: Applied Science and Manufacturing. 2006,37(8):1151 1160 
[4]Weihong Chen. Experimental study on behaviour of concrete beam strengthened with CFRP sheets bonded with inorganic matrix. PhD thesis, Harbin Institute of Technology. 2010:14 32

[5]Wenzhong Zheng, Fuxiong Wan, Shiguang Li. Experimental Research of Refractory Performance of Reinforced Concrete Beams Strengthened with Carbon Fiber Sheet Bonded with an Inorganic Adhesive. Journal of Harbin Institute of Technology. 2010,17(4):568 574 